Supporting Information

\title{
Anti-Adhesive Properties of Oil-Infused Gels against Universal Adhesiveness of Polydopamine
}

Roland Hönes, ${ }^{1 \#}$ Yunhan Lee, ${ }^{2 \#}$ Chihiro Urata, ${ }^{1}$ Haeshin Lee ${ }^{2, *}$, Atsushi Hozumi ${ }^{1, * *}$

${ }^{1}$ National Institute of Advanced Industrial Science and Technology (AIST), 2266-98, Anagahora, Shimoshidami, Moriyama-ku, Nagoya 463-8560, Japan

${ }^{2}$ Korea Advanced Institute of Science and Technology (KAIST), 291 University Rd, Daejeon 305-701, Republic of Korea

*Email: haeshin@kaist.ac.kr

**Email: a.hozumi@aist.go.jp

\# These authors contributed equally to this work.

Number of pages: $\quad 9$

Number of figures: $\quad 4$

Number of schemes: $\quad 0$

Number of tables: $\quad 0$ 


\section{Experimental}

\section{Materials}

Dopamine hydrochloride (Sigma-Aldrich Co., U.S.A.), deionised filtered water (Merck Millipore, Germany), piperidine ( $\geq 98 \%$, Wako, Japan), Sylgard ${ }^{\circledR}$ 184 polydimethylsiloxane (PDMS) elastomer kit (Dow Corning Corp., U.S.A.), polymethylphenylsiloxanes AR20 (Sigma-Aldrich Co., U.S.A.) and TSF437 (Momentive Performance Materials, Japan), isocetane (TCI, Japan), and 2-amino2-(hydroxymethyl)propane-1,3-diol (Tris, ICN Biomedicals Inc., U.S.A.) were used as received without further purification.

\section{Sample Preparation}

To fabricate standard PDMS elastomer, the two components of the PDMS elastomer kit were mixed at the recommended weight ratio of 10:1 (base to curing agent; typical weights were $1.00 \mathrm{~g}$ and $0.10 \mathrm{~g}$, respectively) in $60 \mathrm{~cm}^{3}$ Teflon ${ }^{\circledR}$ containers (about $3 \mathrm{~cm}$ in diameter). After sealing the container tightly, the samples were thoroughly mixed and defoamed by machine (ARE310, Thinky, Japan), and cured at $80{ }^{\circ} \mathrm{C}$ for at least $3 \mathrm{~h}$.

According to our previous reports, ${ }^{[1,2]}$ thermoresponsive self-lubricating gel (SLUG) samples were prepared by mixing the former PDMS precursor mix with two types of silicone oil, that is, AR20 and TSF437 $(2.25 \mathrm{~mL}$ and $0.75 \mathrm{~mL}$, respectively, per $1.00 \mathrm{~g}$ of PDMS base) and subsequent curing under the same conditions. 
Aqueous deposition of polydopamine (PDA) was performed by vertically immersing target substrates (PDMS and SLUG) into a freshly prepared aqueous solution of Tris (2-amino-2-(hydroxymethyl)propane-1,3-diol, $\left.10 \mathrm{mmol} \cdot \mathrm{L}^{-1}\right)$ and dopamine hydrochloride $\left(2 \mathrm{mmol} \cdot \mathrm{L}^{-1}\right)$ in a Teflon ${ }^{\circledR}$ container. The container was left open to the air in a fume hood at room temperature $\left(25-30^{\circ} \mathrm{C}\right)$ for at least $15 \mathrm{~h}$.

\section{Note on Aqueous PDA Deposition}

When lifting the samples out of the reaction bath, a PDA film which had formed on the solution surface ${ }^{[3,4]}$ may be transferred onto the sample. To reduce such undesirable transfer, the samples were moved horizontally in the solution before taking them out, thus rupturing the film close to the samples.

\section{Setup of Imprinting on Lamination Foil}

After aqueous deposition of PDA on both PDMS and SLUG, and drying in air, the samples were placed onto standard commercial lamination foils (Tanosee Lamination Foil TN A4100, Japan) for more detailed optical investigation. In this study, lamination foil was chosen because it is transparent, easy to bend, able to adhere conformally, and does not wrinkle upon contact to liquids like paper. For imprinting, the sample was covered with a second foil (foil-sample-foil) and then compressed manually (low pressure) or by adding a weight on top (equivalent to about $7.2 \mathrm{kPa}$ ). 
Analyses

Optical photographs were taken using the integrated digital camera of a smartphone (LG G4, LG Electronics, Republic of Korea). Optical absorption spectra were acquired using a Cary 5000 spectrometer (Varian Inc., U.S.A.; version 1.12) and the software Cary WinUV (version 4.10) using full zero and baseline correction. All spectra were recorded in the range of $800-200 \mathrm{~nm}$ at a scan rate of $10 \mathrm{~nm} \cdot \mathrm{min}^{-1}$ and a data interval of $1 \mathrm{~nm}$. Dynamic contact angles (CAs) were measured using a DropMaster DM-501 (Kyowa Interface Science, Japan) and the software FAMAS (version 3.7.2), equipped with an electric syringe pump (AD300). First, water droplets of $10 \mu \mathrm{L}$ were placed on the sample surface (the needle of the dosing syringe remained immersed into the droplet). Next, water was gradually added at a rate of $0.5 \mu \mathrm{L} \cdot \mathrm{s}^{-1}$ until the three-phase contact line of the water droplet had moved significantly (visual control) while capturing images. The advancing contact angle $\left(\theta_{\mathrm{A}}\right)$ was determined by analysing the droplet shape in the image at the start of movement of the three-phase contact line using the instrument software. The receding contact angle $\left(\theta_{\mathrm{R}}\right)$ was determined analogously while water was pumped back out of the droplet. Dynamic CAs were gathered at three or more different locations on each surface. The $\theta_{\mathrm{A}} / \theta_{\mathrm{R}}$ values reported are the averages of all these individual values together with the standard deviation. 


\section{Optical Microscopy During Imprinting}

To study the detachment of PDA deposits from both sample surfaces in more detail, optical microscopy was employed during these imprinting experiments. Although PDA was deposited on both samples (Figure S1a and b), the film-like deposits on the SLUG appeared discontinuous with many cracks and voids. After the first imprint at $7.2 \mathrm{kPa}$ for about $30 \mathrm{~s}$, we observed marked differences between these two samples (Figure S1c and d). Although the thickness of the PDA deposits on the PDMS had visibly decreased (colour change, thickness reduced from about $2 \mu \mathrm{m}$ to about $0.5 \mu \mathrm{m}$, as determined by confocal microscopy) and more voids were present than before imprinting, a lot of the PDA deposits still remained. In contrast, apart from very tiny particles, no deposits could be found on the SLUG surface, impressively demonstrating reduced adhesion and easy removal of PDA from this surface. These results clearly indicate that our SLUGs possess a universal antiadhesion property induced by syneresis that effectively prevents PDA adhesion, in spite of PDA having extraordinarily powerful adhesive properties towards various substances, in particular, to highly hydrophobic materials. ${ }^{[5]}$ 


\section{Additional Figures}

(a)

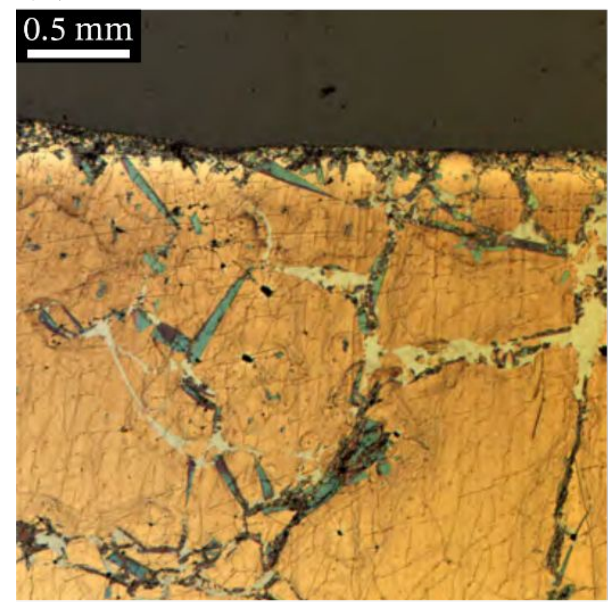

(c)

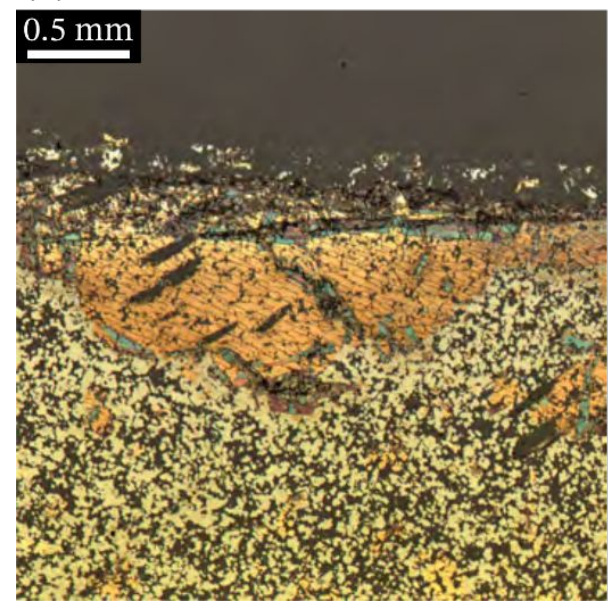

(b)

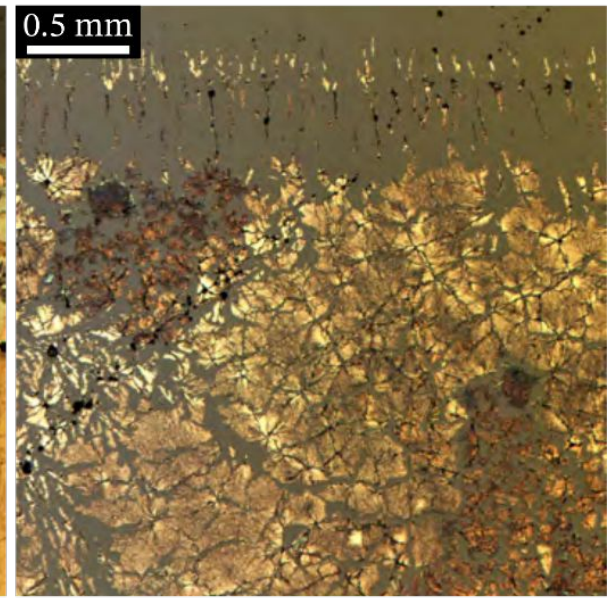

(d)

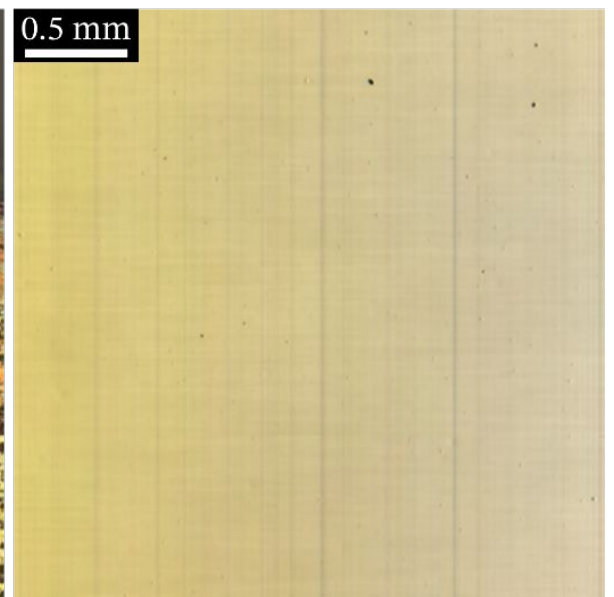

Figure S1. Optical microscopic images of PDA layers deposited on (a) PDMS and (b) SLUG, and (c, d) Identical samples from images (a) and (b) after imprinting at $7.2 \mathrm{kPa}$ for about $30 \mathrm{~s}$ (as shown in Figure 3). Images were taken at the upper immersion edge and include a small part of never-coated region. 
(a)

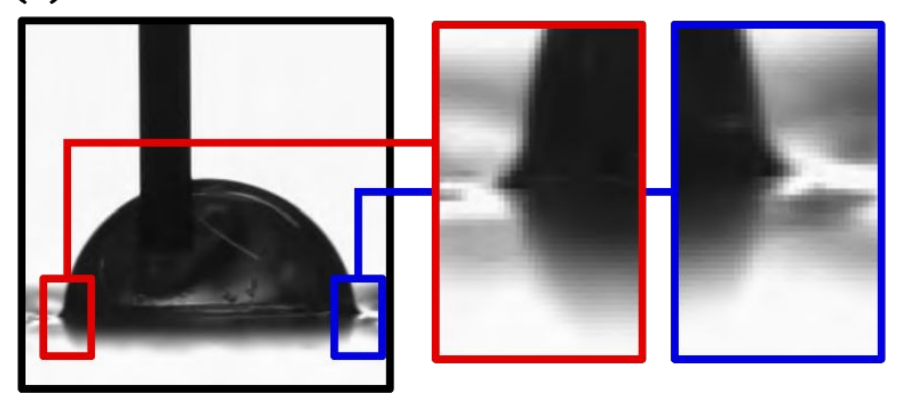

(b)

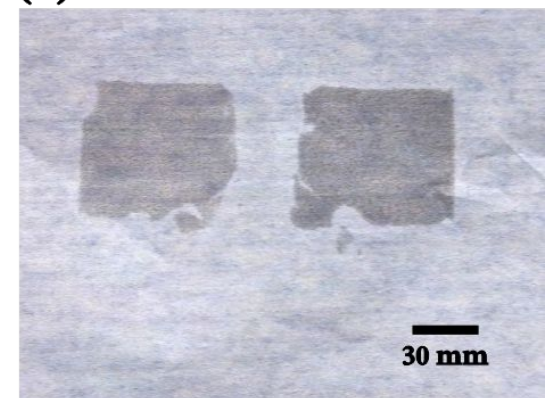

Figure S2. (a) Water droplet profile on a SLUG after cooling to $-20{ }^{\circ} \mathrm{C}$ for more than $3 \mathrm{~h}$ to induce syneresis. Pronounced oil wetting ridges were clearly observed (droplet volume is about $22 \mu \mathrm{L}$ ). (b) Optical image of oil-absorbing blotting paper after a clean SLUG had been laid on it for about $30 \mathrm{~s}$ at room temperature without additional weight, then flipped over from left to right, and removed after another about $30 \mathrm{~s}$ (contrast was enhanced for better visibility).

\section{(a)}

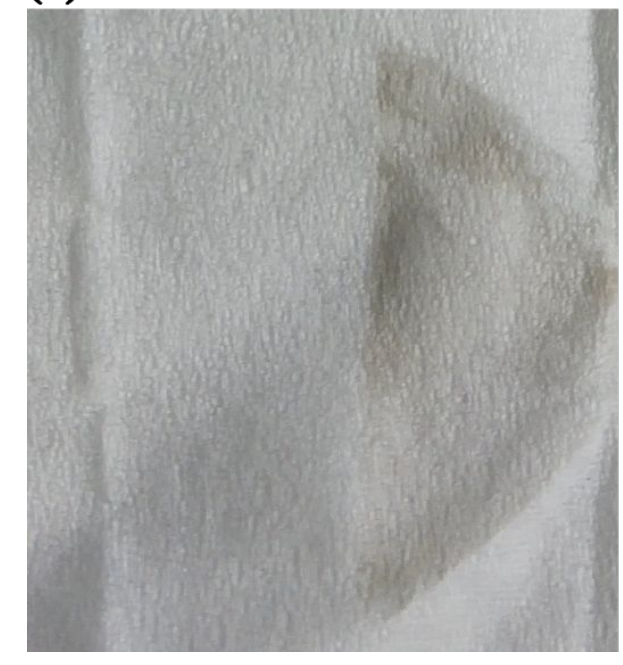

(b)

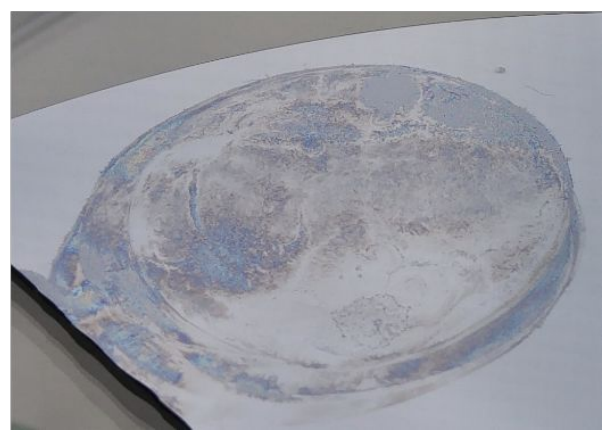

Figure S3. PDA deposits transferred from SLUG to other substrates: (a) Paper towel (no oil transfer from the non-coated part of the sample under these conditions), (b) Clean Si wafer (after inducing syneresis by cooling to $-20{ }^{\circ} \mathrm{C}$ for more than $3 \mathrm{~h}$, transfer of both oil and PDA). In both cases, circular samples of about $3 \mathrm{~cm}$ in diameter were used. 


\section{References}

[1] Urata, C.; Dunderdale, G. J.; England, M. W.; Hozumi, A. Self-Lubricating Organogels (SLUGs) with Exceptional Syneresis-Induced Anti-Sticking Properties Against Viscous Emulsions and Ices. J. Mater. Chem. A 2015, 3, $12626-12630$.

[2] Urata, C.; Hönes, R.; Sato, T.; Kakiuchida, H.; Matsuo, Y.; Hozumi, A. Textured Organogel Films Showing Unusual Thermoresponsive Dewetting, Icephobic, and Optical Properties. Adv. Mater. Interfaces 2018, DOI 10.1002/admi.201801358.

[3] Ponzio, F.; Payamyar, P.; Schneider, A.; Winterhalter, M.; Bour, J.; Addiego, F.; Krafft, M.-P.; Hemmerle, J.; Ball, V. Polydopamine Films from the Forgotten Air/Water Interface. J. Phys. Chem. Lett. 2014, 5, 3436-3440.

[4] Yang, H.-C.; Xu, W.; Du, Y.; Wu, J.; Xu, Z.-K. Composite Free-Standing Films of Polydopamine/Polyethyleneimine Grown at the Air/Water Interface. $R S C A d v .2014,4,45415-45418$.

[5] Zhang, C.; Gong, L.; Xiang, L.; Du, Y.; Hu, W.; Zeng, H.; Xu, Z.-K. Deposition and Adhesion of Polydopamine on the Surfaces of Varying Wettability. ACS Appl. Mater. Interfaces 2017, 9, 30943-30950. 